\title{
Iberescena: reflexões sobre uma ferramenta de fomento ${ }^{1}$
}

\author{
Iberescena: reflexiones acerca una herramienta de fomento
}

Iberescena: reflections on a development tool

\author{
Anderson Albérico Ferreira ${ }^{2}$ \\ Dayenny Neves Miranda ${ }^{3}$
}

\begin{abstract}
Resumo
O presente trabalho pretende trazer uma breve reflexão e um exercício de ambientação ao programa de fomento às artes cênicas, denominado Iberescena, que atualmente, pouco mais de dez anos após sua criação, beneficiou 518 projetos e movimentou cerca de cinco bilhões de euros com o financiamento dos projetos aprovados. Logo, tal programa se caracteriza como um dos principais artífices de fomento ao setor cultural, no âmbito iberoamericano. O objetivo central que se busca com esta pesquisa, é fomentar o estudo e as discussões acerca dessa ferramenta de fomento que tem ganhado cada vez mais destaque. Desta forma, o trabalho é centrado em dois esforços básicos: em linhas gerais, o primeiro consiste em apresentar o programa, abordando sobre sua criação e circunstâncias motes de sua criação; no segundo, busca-se problematizar e provocar questões sobre suas metodologias e operação.
\end{abstract}

Palavras-Chave: Fomento; Ibero-América; Cooperação Cultural; Iberescena; Políticas Culturais.

\section{Resumen}

El trabajo que sigue busca reflejar el programa de fomento a las artes escénicas, denominado Iberescena que actualmente, diez años tras su creación, ha apoyado 518 proyectos con sus becas, así como ha aplicado cerca de 5 billones de euros a la financia de los proyectos apoyados. Puesto ello, este programa se caracteriza como una de las principales herramientas de fomento al sector cultural, en el ámbito de Iberoamérica. Sin embargo, el eje de este estudio introductorio es nada más que articular el debate acerca del referido programa, que ha ganado cada vez más destaque. Luego, el trabajo viene presentar el programa, describiendo su creación y los factores imbricados a ella; en un segundo momento, intentamos problematizar y provocar cuestiones acerca de sus metodologías y operación.

Palabras claves: Fomento; Iberoamérica; Cooperación Cultural; Iberescena; Políticas Culturales.

\begin{abstract}
This paper intends to bring a brief reflection and an ambience exercise of Iberescena, a program that promotes performing arts, wich today, after less than ten years of existence has benefited 518 projects and handled about five billion euros financing these approved projects. Therefore, this program is characterized as the main tool to the cultural sector in the Ibero-American context. The main objective of this paper is to encourage the study and the discussion about this tool who has gained more importance each time. Thus, this research goes in two paths:
\end{abstract}

\footnotetext{
1 Artigo apresentado no Simpósio Temático Jovens Pesquisadores Latino-americanos durante o II Seminário Latino-Americano de Estudos em Cultura - SEMLACult em Foz do Iguaçu/PR, Brasil, 2018.

${ }^{2}$ Graduando em Produção Cultural; Instituto de Educação, Ciência e Tecnologia do Rio de Janeiro - IFRJ; Nilópolis, Rio de Janeiro, Brasil; andersonfolks@gmail.com

${ }^{3}$ Doutora em Letras Neolatinas; Universidade Federal do Rio de Janeiro - UFRJ; Rio de Janeiro, Rio de Janeiro, Brasil; dayenny@ hotmail.com
} 
first present the program, it's creation and it's specificities; and second, it seeks to problematize and raises the discussion about its methods and operations.

Keywords: Development; Ibero-America; Cultural Cooperation; Iberescena; Cultural Policies.

\section{Introdução}

A cultura, sem dúvidas, se tornou em um dos mais representativos signos da modernidade. Apresenta-se não só como um novo campo laboral e de estudo, mas como um mecanismo de conquista - sendo um espaço de disputas e dinâmica de poder - e de invenção - produzindo e fomentando identidades sociais. Atualmente notamos certa efervescência e urgência quanto ao seu debate, devido ao espaço cada vez mais central que vem ocupando nas dinâmicas não só sociais, mas também nas políticas e econômicas (HALL, 1997; YÚDICE, 2002). Tal fato pode ser observado com maior clareza a partir de meados do século XX, momento o qual o campo simbólico, como diria Bourdieu, passa a ser compreendido cada vez mais como vetor de desenvolvimento, crescimento e poder, visto sua grande penetração e ressonância social.

Contudo, esse movimento de centralidade da cultura, como aponta Stuart Hall (1997), pode ser compreendido como mais um resultado de um processo complexo e mais antigo, que de forma pretensiosa denominamos de movimento da história da cultura, já que a cultura em diversos momentos da história da humanidade exerceu inúmeros papéis e, como bem expressa Georg Yúdice, lhe foi dado vários "usos". Um desses usos que mais tem influência na sociodinâmica cultural de nossos dias foi aquele concebido pelo progressismo do século XIX. Neste período a relação entre cultura, economia e política passam a ser estreitar cada vez mais, ousamos dizer que até se confundiram em determinado momento. Percebemos que a cultura vai exercer o papel de uma "tecnologia de controle", ideia que vai ser deixada de legado para o século XX, com a indústria cultural por exemplo. Será evocado nesse momento os profundos laços históricos da cultura com o campo político, o que despontará desde a estetização da política, abordada por Walter Benjamim (1994), até a politização das artes e da cultura.

Diante dessa potencialidade da cultura, do desgaste do progressismo enquanto ideologia e do abalo da comunidade internacional pós-guerra, um espírito de suposta fraternidade e cooperação internacional ecoará em prol da estabilidade entre as nações fomentando a criação de diversos organismos internacionais. Mais uma vez a cultura terá um 
novo uso, agora exercerá o papel de "liga" para juntar os fragmentos da confiança da comunidade internacional, e o desenvolvimentismo, enquanto ideologia, será a mão que aplicará essa "cultura cimentadora".

Neste contexto, diversos países e organismos internacionais passam a desenvolver e pensar ações de organização e institucionalização de entidades, programas e políticas de forma a fomentar e democratizar o campo da cultura, com o objetivo de se promover um desenvolvimento tanto social, como econômico (CALABRE, 2005; BAYARDO, 2007). Identificamos que o marco desse movimento toma forma na década de 1980, momento o qual ocorre uma das primeiras iniciativas de se pensar políticas culturais em nível internacional, o Mondiacult (Conferência Mundial sobre Políticas Culturais). Tal conferência, promovida pelo organismo multilateral UNESCO (Organização das Nações Unidas), foi um espaço no qual várias nações se reuniram para alinhavar questões e perspectivas, bem como refletir sobre as nuances, matizes e especificidades do campo cultural que desempenhava, desde o século XIX, um papel cada vez mais central e estratégico. Nesse movimento de construção de ações voltadas à cultura surgem, sobretudo na América Latina e Ibero-América, inúmeros programas e projetos de fomento, integração e cooperação cultural, dentre eles destacamos o programa Iberesecena, criado em 2006, que surge como uma iniciativa da SEGIB (Secretáriageral Ibero-americana) que visava criar um fundo de fomento às Artes Cênicas da IberoAmérica, na busca de fomentar o setor e criar uma rede internacional.

Posto isso, o presente trabalho é o resultado, preliminar, de uma análise qualitativa dos dados levantados a partir de uma pesquisa documental - leis, regulamentos e relatórios - e da revisão bibliográfica - textos teóricos -, no intuito de provocar e fomentar a reflexão sobre este programa de fomento que tem se caracterizado como uma das principais fontes de fomento e cooperação cultural da Ibero-América.

\section{Cultura e Desenvolvimento: Um ponto de partida}

Atualmente é quase que inconcebível pensar cultura sem falar de desenvolvimento, esses dois termos são tão próximos hoje, que é comum entender que a ideia de desenvolvimento foi a precursora e impulsora do processo sistematizado do Estado pensar cultura. No entanto, o campo simbólico começou a tomar uma dimensão significativa, no que se refere a construção da sociedade ocidental moderna, a partir das ressignificações e dos empreendimentos progressistas do século XIX. Para compreender melhor esta ideia, é importante grifar a perspectiva de Alain Touraine, a qual concebe "a sociedade moderna 
como força de liberação e criação [grifo nosso]" (RAMOS, 2013, p. 24). Em suma, em nome do progresso diversos campos e aspectos da vida e da trama social paulatinamente passaram a ter novos "usos", e com o campo cultural não foi diferente, sobretudo a arte e a educação funcionaram como artífices dessa suposta possibilidade libertadora e criacionista.

O advento da modernidade, enquanto reorganização da vida e da sociedade, teve influência direta do Iluminismo: crescimento, racionalidade, "liberdade", necessidade, cálculo, controle... em suma progresso, essa será a bandeira do pensamento do Iluminismo. Ao passo que a ideia de cultura que estará ligada a essa corrente ideológica será a de civilização, que de acordo com o sociólogo Norbert Elias (2011, p. 23),

\footnotetext{
"assume tudo em que a sociedade ocidental dos últimos dois ou três séculos se julga superior a sociedades mais antigas ou a sociedades contemporâneas 'mais primitivas'. Com essa palavra, a sociedade ocidental procura descrever o que lhe constitui o caráter especial e aquilo de que se orgulha: o nível de sua tecnologia, a natureza de suas maneiras, o desenvolvimento de sua cultura científica ou a visão do mundo, e muito mais."
}

Essa preferência por civilização em vez de cultura não é um acontecimento isolado, uma mera ação de escolher palavras. Os sentidos dados e imbricados a esses conceitos deveriam estar em consonância ao ideário e aos novos paradigmas propostos. Mesmo que o campo simbólico ou, nas palavras de Eagleton (2011:10), as verdades culturais $^{4}$ se apresentassem como uma peça-chave para a liberdade e a centralidade do homem nesse novo "mundo" proposto pelos iluministas, o produto desse "homem", ou uma espécie de resultado final do polimento da matéria bruta - "autocultura" -, cada vez mais parecia ser a civilização.

Em paralelo a essa reorganização do uso da cultura, o capitalismo vai tomar uma dimensão cada vez maior nessa sociedade devido a concepção de que a divisão do trabalho cumpriria o papel civilizatório de potencializar e distribuir riquezas (SMITH apud HOBSBAWM, 1982), de forma que os bens culturais, o capital cultural como diria Bourdieu, se convertiam cada vez mais em bens de consumo. Como problematiza Walter Benjamin (1999), em seu ensaio "A obra de arte na era de sua reprodutibilidade técnica", sobre os rumos e as tendências do campo simbólico, especificamente da arte, diante à realidade social e as condições "reprodutivas" da arte no século XX. A cultura se aproximava cada vez mais da economia, alguns críticos mais ferozes dirão que ela se contaminava, dado que a lógica capitalista é excludente, massificante e empobrecedora de toda a carga e riqueza simbólica,

\footnotetext{
${ }^{4}$ Terry Eagleton em sua obra "A ideia de cultura" (2011, p. 10) define Verdades culturais como a arte elevada e as tradições de um povo.
} 
pois a reprodutibilidade nada mais seria que o esvaziamento da áurea, autenticidade e a unicidade, em suma da identidade. A organicidade e transitoriedade, o permissivo-restrintivo da cultura, se torna algo mecânico e seriado.

Posterior ao desgaste das ideias progressistas no século XX, o desenvolvimentismo, herdeiro direto do progressismo, surge como uma nova ideologia, teoricamente, orgânica. A ideia de progresso vai perdendo força, dado os resultados onerosos à sociedade global resultantes da Primeira Guerra Mundial (1914-1918), motivada sobretudo por um ambiente de predatismo econômico ${ }^{5}$ fomentado pela lógica capitalista (HOBSBAWM, 1995, p. 37). Por assim dizer, essa nova concepção tem sua gênese entre os anos de 1930 e 1940, é cunhado no intuito de se defrontar contra o atraso, a incompreensão, a violência, o poder oligárquico e outras formas de atraso (BURITY, 2007, p. 55). Porém é na década de 1950, logo após a segunda Guerra mundial (1939-1945), que o imaginário desenvolvimentista se torna triunfante enquanto ideologia. Concomitante a esse processo, surge nesse mesmo período do pós-guerra todo um processo de reorganização das relações internacionais, a primeira ação na busca de reaver os laços, bem como a confiança internacional e também propor um pacto e espaço que viesse a impedir outro conflito bélico daquela magnitude, é a criação da ONU (Organização das Nações Unidas) em 1945. Desde a constituição deste órgão intergovernamental a cooperação, bem como, a lógica dos órgãos de caráter internacional passa a ganhar força e serem considerados como uma ferramenta elementar no processo de reorganização mundial, suscitada pelo pós-guerra. Tais concepções passaram a ser articuladores do imaginário, modelos e ações desenvolvimentistas.

Dentro da lógica progressista o componente econômico ocupava a posição central na concepção de uma sociedade próspera e civilizada, em contraponto o desenvolvimentismo, sobretudo nas décadas finais do século XX, ao menos teoricamente, extrapola as concepções de que a "riqueza" se concentra unicamente na unidade econômica, os componentes social e cultural passam a ser entendidos como articuladores e fomentadores do processo de desenvolvimento. Como pontua o pesquisador Guy Hermert (2002, p. 33),

"o desenvolvimento não vai se inserir somente na esfera da técnica econômica. Ao contrário: baseia-se no diagnóstico documentado de um resíduo estrutural resultante de causas múltiplas e entrelaçadas, passível de um processo de modernização social e cultural governado desde o cume, que irá

\footnotetext{
5 Trata-se de uma disputa "selvagem" por fatores que historicamente sempre denotaram poder: hegemonia territorial e econômica. Dentro da lógica capitalista materialista, a questão de poder relacionava-se a quantidade do capital que se detinha, ao poderio econômico, sendo assim, a detenção de vários territórios era fundamental para criação e manutenção de um império econômico.
} 
se estender a todas as camadas da população, não se limitando ao aparato da produção."

Logo, podemos notar que os componentes cultural e social passam a fazer parte do arcabouço teórico que compreende a noção de desenvolvimento. Entendemos que se passou a notar que o campo simbólico representava uma ferramenta fundamental para as sociedades dado que a cultura é uma trama simbólica que "aparece como a condição da própria existência humana, pois é pela cultura que aquela existência adquire a sua verdadeira significação e o sentido do seu próprio destino" (FERNADES, 1988, p. 125). A cultura passa a ser entendida como um vetor de desenvolvimento, pois ela passa a assumir nesse momento

"uma função de importância sem igual no que diz respeito à estrutura e à organização da sociedade moderna tardia, aos processos de desenvolvimento do meio ambiente global e à disposição de seus recursos econômicos e materiais. Os meios de produção, circulação e troca cultural, em particular, têm se expandido através das tecnologias e da revolução da informação." (HALL, 1997, p. 17)

Mesmo diante dessa transformação do "lugar" da cultura na sociedade moderna, ou seja, sua centralidade, é importante não romantizarmos quanto a essa questão, como expõe Burity (2007, p. 57) por bastante tempo a lógica econômica virulenta do discurso neoliberal, de que a economia era, ou deveria ser, a mola mestra da construção social, espraiando-se ante outros campos, tais como a política, sociabilidade cotidiana e etc., esteve presente no imaginário de vários lugares do mundo. Assim posto, é possível notar uma certa "queda de braços" quanto o lugar de centralidade na modernidade tardia, de um lado a, historicamente, soberana economia se vê afrontada pela emergente cultura. No entanto, George Yúdice (2002, p. 23-24) assinala que mesmo que a cultura houvesse se convertido em um mero pretexto para o progresso sociopolítico e o crescimento econômico, a proliferação desses argumentos nos foros onde se discutem projetos tocantes à cultura e ao desenvolvimento local nos organismos e instituições governais, intergovernamentais e não governamentais, transformaram e passaram a direcionar o conceito de cultura e fomentar o debate do campo e do que se fazemos em seu nome.

\section{Cooperação Cultural: a cultura como recurso}

No processo de transição e novos usos dados a cultura observamos que a participação de órgãos governamentais, não governamentais e intergovernamentais tem sido singular e protagonista na concepção de políticas culturais e no fomento ao campo da cultura. Nesse 
contexto, a cooperação cultural se converteu nos últimos anos, principalmente, no contexto da Ibero-América, em um instrumento determinante na articulação dessas políticas. Os governos e organismos passaram a pensar em políticas voltadas à cultura não só no âmbito nacional, mas também no âmbito internacional. Ela tem atuado como uma ferramenta estratégica quanto ao asseguramento da diversidade cultural diante a globalização e o crescente processo de migrações, de forma a "garantir uma interação harmoniosa e fomentar a convivência pacífica e respeitosa entre pessoas e grupos com identidades culturais plurais, variadas e dinâmicas" (FÉRRIZ \& PONSÀ, 2007, p. 11).

A UNESCO possui um importante papel na constituição desta nova onda de cooperativismo internacional (FLORES \& MIGUEZ, 2015), a partir do momento, em que promove a Declaração dos princípios da Cooperação Internacional na décima quarta reunião da Conferência Geral, em 1966, na cidade de Paris. Surgiu como uma forma de assegurar os direitos culturais, e a diversidade cultural, diante o contexto de um mundo globalizado e com uma gama cada vez maior de migrações. A UNESCO concebeu a cooperação cultural pensando em sua funcionalidade prática, em suma ela seria toda ação de cooperação que despontasse no desenvolvimento, marca ideológica da segunda metade do século XX, e que tivesse a finalidade de difundir o conhecimento, desenvolver relações pacíficas e amistosas entre as nações, em suma, aplicar o princípio das Nações Unidas. Nesse primeiro momento a cooperação cultural exercia o papel de um mero instrumento diplomático que usava a promoção exterior da cultura como metodologia de aplicação. Tal declaração tinha por finalidade elencar princípios que norteassem e amparassem ações voltadas ao campo cultural dentro da lógica do desenvolvimentismo. Sendo assim, a declaração foi criada

"a fim de que os governos, autoridades, organizações, associações e instituições que estão a cargo de atividades culturais, tenham constantemente em conta tais princípios, e possam alcançar gradualmente, como se afirma na Constituição da Organização - mediante a cooperação das nações do mundo nas esferas da educação, ciência e cultura - os objetivos de paz e de bem-estar enunciados na Carta das Nações Unidas." (UNESCO, 1966)

De acordo com os pesquisadores Alicia Flores e Paulo Miguez (2015) a Declaração de Princípios da Cooperação Cultural Internacional (1966) terá o caráter não de sistematizar e institucionalizar uma concepção teórica e sistemática sobre o que seria cooperação cultural, o marco regulatório "estabeleceu uma justificativa, um conjunto de valores e propósitos que norteariam sua ação" (idem, p. 111). Sendo assim, observa-se que não há uma definição exata do que seria a cooperação cultural, os artigos que constituem a declaração têm caráter de 
descrição da amplitude das ações de cooperação, formas possíveis de ação e princípios básicos que devem ser atendidos, como podemos observar nos dois artigos que seguem.

\section{Artigo III}

A cooperação cultural internacional abarcará todas as esferas de atividades intelectuais e criadoras nos campos da educação, ciência e cultura.

\section{Artigo IV}

As finalidades da cooperação cultural internacional, em suas diversas formas bilateral o multilateral, regional o universal - são:

1. Difundir os conhecimentos, estimular as vocações e enriquecer as culturas;

2. Desenvolver as relações pacíficas e a amizade entre os povos, levando-os a compreender melhor seus modos de vida;

3. Contribuir à aplicação dos princípios enunciados nas declarações das Nações Unidas a que se faz referência no preâmbulo da presente Declaração;

4. Fazer que todos os homens tenham acesso ao saber, desfrutem das artes e das letras de todos os povos, se beneficiem dos progressos logrados pela ciência em todas as regiões do mundo e dos frutos que deles derivam, e possam contribuir, por sua parte, ao enriquecimento da vida cultural;

5. Melhorar em todas as regiões do mundo as condições da vida espiritual do homem e as de sua existência material. (UNESCO, 1966)

Ramón Férriz e Fransesc Ponsà (2007, p. 17) são dois pesquisadores que buscam organizar teoricamente o que seria cooperação cultural, ambos a entendem como "todas as intervenções relacionadas com o âmbito cultural que ampliem a liberdade das comunidades receptoras, incrementem seus recursos e seu sentido de pertencimento e os conceda maior acesso à informação e ao conhecimento em geral”. Mesmo diante do esforço de pesquisadores por uma construção teórica, percebemos que a ausência de um norte teórico que parta da UNESCO dificulta uma maior projeção e assertividade quanto a construção de redes de cooperação cultural. Além disso o "vazio" conceitual viabiliza precedentes e ações contrárias, ou equivocas, à ideia central de desenvolvimento e transformação, tanto social, como cultural, que a ideia de cooperação cultural aspira. Muitas das vezes tem-se confundido cooperação com promoção cultural, sendo que a última é um dos possíveis desdobramentos da primeira.

É especificamente nos anos 1990, com o surgimento da ideia de desenvolvimento humano, que a ideia de cooperação cultural vai ser reinventada. Até esse momento um 
enfoque puramente economicista era a mola propulsora da cooperação cultural que se colocava em prática. Como apontam Férriz e Ponsà (2007) o desenvolvimento humano implicaria não só a necessidade de se atender as necessidades físicas, habilitadoras e sociais dos indivíduos e das populações, mas àquelas que não são proporcionadas unicamente por vias econômicas, que se localizam no bojo do campo simbólico, essas são riquezas que podem gerar potentes ferramentas motrizes para o desenvolvimento humano.

É válido destacar que a cooperação cultural, mesmo que tenha se tornado nos últimos anos um objeto de estudo e investigação cada vez mais recorrente, ainda caracteriza-se por não ser um âmbito claramente definido, como Ramón Férriz e Fransesc Ponsà (2007, p. 14) discorrem, “[...] [a cooperação cultural] ainda não é um âmbito claramente definido nem, ainda, foi incorporado com nitidez nas políticas tanto culturais, como de cooperação, em boa parte das instituições mundiais". Observamos ainda que haja um notável processo de desenvolvimento de ações de cooperação cultural, esta ainda não é um artífice "universal" dentro do bojo de ferramentas de fomento ao desenvolvimento.

Mesmo diante deste certo hiato conceitual, há muitos esforços, atividades e organismos que surgem no objetivo de promover uma cooperação para o desenvolvimento. Mencionamos a OEI (Organização de Estados Ibero-americanos para Educação, Ciência y Cultura), uma das primeiras organizações multilaterais da ibero-américa, que se caracteriza como "um organismo internacional de carácter governamental para cooperação entre os países ibero-americanos no campo da educação, ciência, tecnologia e cultura no contexto do desenvolvimento integral, democracia e integração regional”. Este ente surge quase que concomitantemente a criação da UNESCO, sendo a última criada em 1946, enquanto a OEI surge três anos depois, em 1949, abrindo espaço para a criação de novas organizações dessa natureza na região. Ambas organizações trabalham especificamente no mesmo campo, o desenvolvimento em todas suas formas - cultural, humano, econômico etc. -, sendo que a OEI se destina aos países ibero-americanos dados suas particularidades históricas, sociais, econômicas e culturais. Dentre as realizações da OEI, damos destaque a criação da SecretariaGeral Ibero-americana (SEGIB), no ano de 2003, na XIII Cúpula de Chefes de Estado e de Governo momento o qual os países decidem criar um organismo que se encargaria de garantir suporte técnico para os 22 países-membros das cúpulas ibero-americanas, sendo eles: 19 da América Latina de língua espanhola e portuguesa e Espanha, Portugal e Andorra, na Península Ibérica. 
Figura 1 - Países membros da OEI

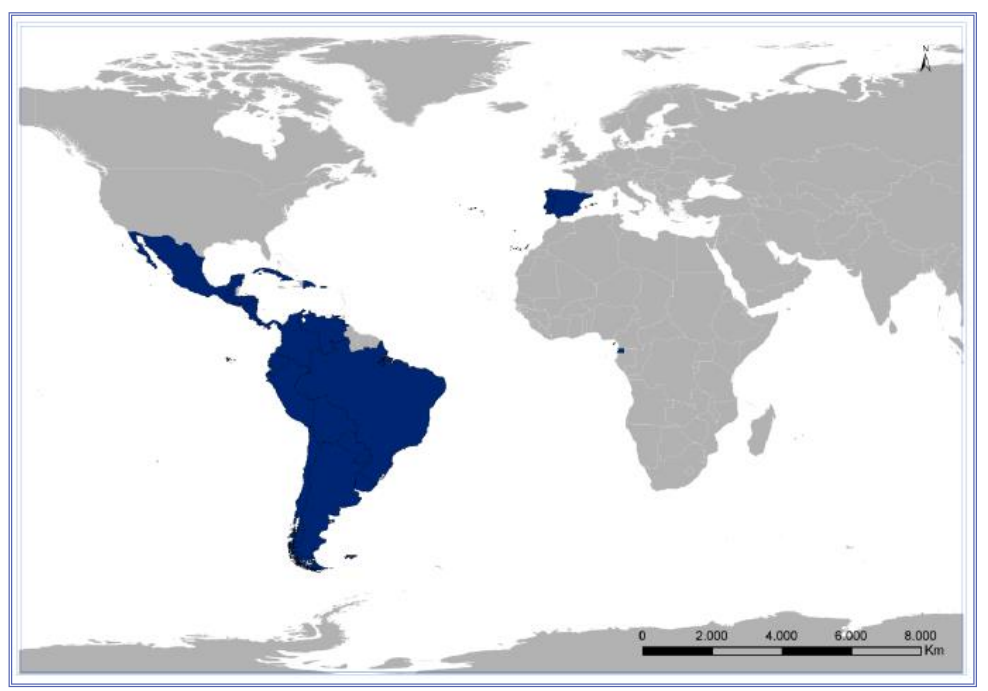

Fonte: (VILLARINO \& ZANABRIA, 2015)

Esse organismo internacional tem como objetivo principal dar cumprimento aos mandatos da Organização das Cúpulas Ibero-Americanas de Chefes de Estado e de Governo e promover a Cooperação Ibero-Americana nos âmbitos da educação, coesão social e cultura, além de:

1. Fortalecer a comunidade ibero-americana e assegurar a sua projeção internacional;

2. Promover as relações históricas, culturais, sociais e econômicas entre os países ibero-americanos, valorizando a diversidade entre os seus povos

3. Apoiar a preparação das Cúpulas Ibero-Americanas de Chefes de Estado e de Governo e dar cumprimento aos seus mandatos

4. Implementar e fortalecer a cooperação sul-sul na região, nas áreas prioritárias da educação, cultura e coesão social. (PORTAL SEGIB)

Neste sentido a SEGIB e a OEI buscam alinhavar os matizes e particularidades da gestão pública de cada país, promovendo ferramentas que promovam o desenvolvimento econômico e social. No caso da cultura não é diferente, após a Conferência Mundial sobre Políticas Culturais (Mondiacult) organizado pela UNESCO as temáticas que giravam em torno da cultura, e especificamente sobre politicas culturais se tornam cada vez mais imperativas na agenda de um país que possuía um desenho de politica pública consistente e que buscava o desenvolvimento de sua nação. Nas décadas seguintes, sobretudo na de 1990, observamos um notável movimento de organização e sistematização do pensar e articular política cultural, no contexto da América Latina por exemplo, países como Bolívia, Equador, Paraguai, Argentina, Brasil, Chile y México, começam a articular ministérios para gerirem a 
pasta de cultura. Diante a criação de toda essa institucionalidade da cultura em cada país, e o compromisso da OEI com a cultura, o organismo passou a desenvolver foros, atividades e projetos que fossem de encontro com as necessidades partilhadas pelos Estados-membros.

A cooperação ibero-americana no campo da cultura está organizada em um conjunto de diversos programas, que na sua grande parte estão baixo a chancela "iber". Dentro do bojo de atividades desenvolvidas por esse organismo destacamos as iniciativas que tem como objeto central de políticas culturais e fomento eixos elementares a toda agenda cultural. Em suma, são pilares de sua política para a cultura ações voltadas ao patrimônio e às distintas vertestes das artes - tais como as cênicas, visuais, música, etc. - que tem, no âmbito de cooperação cultural, programas estabelecidos e em funcionamento. Dentre eles Villarino e Zanabria (2015) apontam que são quatro programas iber que possuem destaque, o programa Ibermuseus, programa Ibermúsicas, programa Ibermedia e programa Iberescena, o qual dedicamos nossa análise.

\section{Fomento as Artes Cênicas: Iberescena}

O programa denominado Iberescena (Programa Ibero-americano de Cooperação para as artes cênicas) surge como uma nova ferramenta de fomento ao setor das artes cênicas e performáticas. Tal programa faz parte de um conjunto de ações de cooperação iberoamericana desenvolvidas pela SEGIB, voltadas ao campo cultural. Sua criação foi inspirada em outra iniciativa "iber", o programa ibermedia que se caracteriza como uma iniciativa de incentivo à coprodução de filmes de ficção e documentários. Neste contexto, cria-se em 2006 o Fundo de ajuda para as Artes Cênicas Ibero-americanas, tendo como base as decisões adotadas pela Cúpula Ibero-americana de Chefes de Estado e Governo, celebrada em Montevidéu (Uruguai), que regulamentavam a execução de um programa de fomento, intercâmbio e integração das atividades das Artes Cênicas ibero-americanas. Nesse primeiro momento se estabelece a criação de um fundo comum, integrado pelas cotas dos países integrantes aderentes a iniciativa, a fim de viabilizar o projeto Iberescena que se estava desenhando. Inicialmente foram oito países que integraram o programa: Argentina, Colômbia, Chile, Equador, Espanha, México, República Dominicana e Venezuela, cada qual foi representado por uma autoridade a fim de conceber e construir o Regulamento de Funcionamento do Programa Iberesecena (2006), documento que nortearia o escopo das chamadas de editais de fomento, que se iniciariam no ano de 2007. Segundo esse documento o Iberescena será descrito como um projeto multilateral de cooperação técnica e financeira 
para fomentar o desenvolvimento das Artes Cênicas, especificamente nos campos do teatro e da dança contemporânea da região ibero-americana. De acordo com o Portal Iberescena, se busca com a iniciativa:

1. Promover montagens cênicas com linguagens inovadoras e novas expressões que dialoguem com a cena contemporânea;

2. Fomentar a distribuição, circulação e promoção de espetáculos iberoamericanos;

3. Incentivar as coproduções de espetáculos entre produtores públicos e/ou privados da cena ibero-americana e promover a sua presença no espaço cênico internacional;

4. Promover a criação de montagens cênicas de obras de autores iberoamericanos;

5. Apoiar os espaços cênicos e os festivais Ibero-americanos, priorizando em sua programação produções regionais;

6. Favorecer o aperfeiçoamento profissional no setor das artes cênicas;

7. Promover a colaboração e sinergia com outros programas e instâncias relacionadas às artes cênicas;

8. Promover a criação de projetos que incluam as temáticas sobre gênero, povos originários e afrodescendentes e/ou que favoreçam a coesão e inclusão social.

No ano de 2007, o Iberescena, através de suas chamadas, pretendia promover aos artistas e produtores dos Estados-membros auxílio financeiro, além de fomentar um espaço de integração para as Artes Cênicas. Atualmente a iniciativa está composta por quatorze países que o financiam, sendo eles: Argentina, Bolívia, Brasil, Colômbia, Chile, Costa Rica, Equador, El Salvador, Espanha, México, Panamá, Paraguai, Peru e Uruguai, além da Secretaria-Geral Ibero-americana (SEGIB).

FIGURA 2 - Países integrantes do programa Iberescena

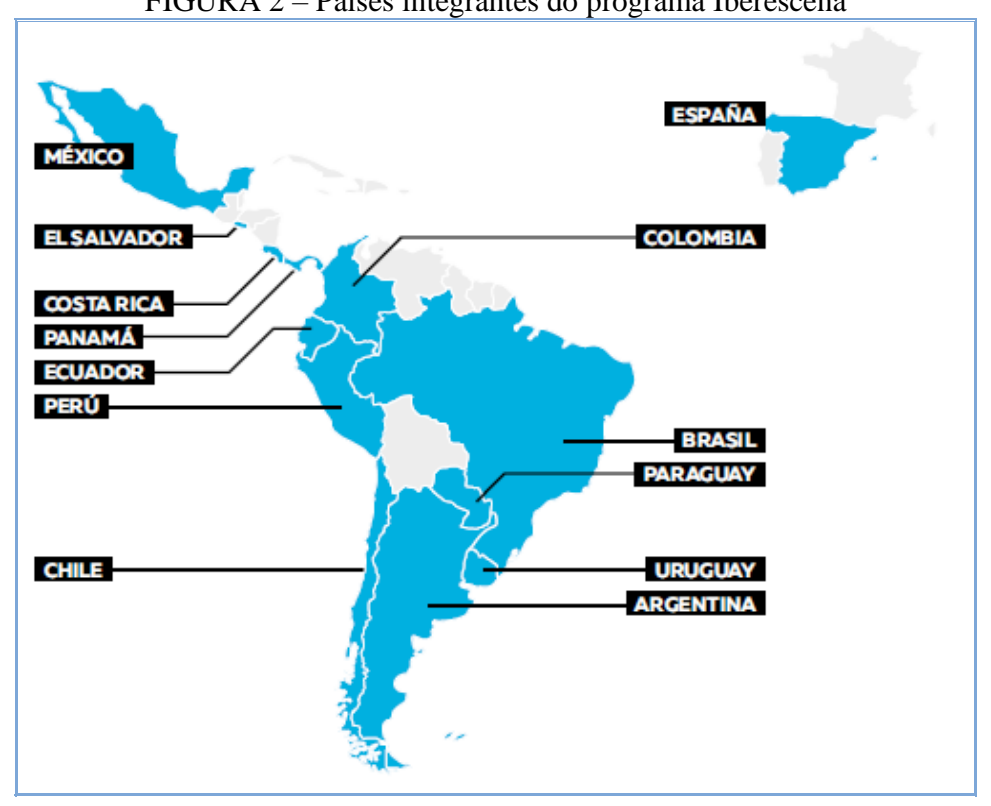


Fonte: (PACHECO, 2017)

Sua direção fica a cargo do Comitê Intergovernamental Iberescena, (CII) no qual cada Estado-membro designa uma autoridade da área das Artes Cênicas como seu representante, tais representações são denominadas de Ponto Focal. Desta forma, fica a cargo deste Comitê definir a política e as modalidades de apoio, sempre em conformidade com as regras enunciadas no Regulamento de Funcionamento do Programa Iberescena (2006), além de

1. Definir as funções da Unidade Técnica do IBERESCENA e designar a seu secretário;

2. Aprovar os relatórios e indicadores do ano anterior, bem como o orçamento do próximo exercício fiscal;

3. Aprovar e definir o Plano Operativo Anual;

4. Ordenar as auditorias correspondentes;

5. Avaliar e dar seguimento ao desenvolvimento do programa, podendo definir sua renovação a cada três anos;

6. Definir anualmente as convocatórias do programa, os Projetos Especiais e os Projetos de Sinergia;

7. Aprovar o montante dos aportes mínimos e a distribuição dos recursos do fundo, para cada uma das convocatórias, bem como para os Projetos Especiais e os Projetos de Sinergia;

8. Estabelecer todas aquelas ações que estime pertinentes para o logro dos objetivos do programa;

9. As restantes funções estabelecidas no ponto 8.1 do Manual Operativo da Cooperação Ibero-americana aprovado na XX Cúpula Ibero-americana de Mar de Plata (2010). (URUGUAI, 2006)

O marco regulatório de funcionamento do programa define ainda que deve ocorrer ao menos uma reunião ordinária do Comitê, assim como todas aquelas que se considerem extraordinárias, a fim de decidir quais projetos serão apoiados e a quantia que fomentará os mesmos, garantindo, desta forma, a organicidade e a manutenção da característica fundamental do programa que é a concepção transnacional, que o Conselho adota no processo de escolha dos projetos. Dentro desta estrutura, a Unidade Técnica do Iberescena (UTI) assume a responsabilidade de dar cumprimento as convocatórias de ajuda e garantir que os projetos aprovados cumpram com os requisitos dispostos nos editais das chamadas, em resumo cabe a UTI o papel de executora e mantedora do funcionamento do programa.

No que concerne a sua operação, atualmente as linhas de ajuda se estruturam em três concepções básicas: 1. Ajudas a Festivais e Espaços Cênicos para a programação de espetáculos; 2. Ajudas à Coprodução de espetáculos ibero-americanos de Artes Cênicas e 3.Ajudas a Centros ibero-americanos de criação Cênica em residência. Tais linhas de ajuda são oferecidas através de editais específicos, nos quais são expostas as diretrizes e dinâmica de participação, bem, como os critérios de seleção. É válido sinalar que a forma como o 
programa é inserido e aportado em cada país é variável, devido as particularidades e realidades de cada país-membro. Por exemplo, no Brasil o programa tem como objetivo complementar as políticas de fomento nacional e local, a fim de facilitar e/ou gerar o intercâmbio de artistas e produtores, possibilitando uma troca e experimentação para além dos limites territoriais. Outro ponto que merece destaque é que até o ano de 2013 o programa contava com uma quarta linha de ajuda denominada de Programas de formação orientados a gestores e produtores de artes cênicas ibero-americanos, presente na tabela a seguir.

Tabela 1. Linhas de ação do programa Iberscena até 2013

\begin{tabular}{ll}
\multicolumn{1}{c}{ Concepção } & \multicolumn{1}{c}{ Linhas de ajuda } \\
\hline CIRCULAÇÃOO & $\begin{array}{l}\text { Ajudas a festivais e espaços cênicos para a } \\
\text { programação de espetáculos }\end{array}$ \\
\hline AUTORIA & $\begin{array}{l}\text { Ajudas a Centros Ibero-americanos de criação cênica } \\
\text { em residência }\end{array}$ \\
\hline COPRODUÇÃO & Ajudas a coprodução de espetáculos ibero- \\
& americanos de artes cênicas. \\
\hline FORMAÇÃO & Ajudas ao desenvolvimento de montagens autorais \\
& no contexto cênico da Ibero-América
\end{tabular}

Fonte: Elaboração do autor, baseado nas informações do Portal IBERESCENA

Em 2011 se cria uma linha de fomento denominada Projetos Especiais, que nada mais são projetos que não se aplicam nas demais linhas de ajuda. Esses projetos devem ter como objetivo fortalecer o crescimento de iniciativas regionais existentes ou resolver situações, problemas ou lacunas detectadas. Para tanto, a metodologia de seleção é baseada em análises que mostrem a necessidade ou importância desses projetos, bem como sua contribuição para os processos de integração no espaço cênico ibero-americano. Eles devem justificar seu caráter inovador e/ou sua relevância social, cultural e artística. No caso de projetos regionais, isto é, aqueles que reúnem vários países da região, devem igualmente justificar sua conexão com o resto da América Latina. (PACHECO, 2017, p.13-14). Cada projeto deve contar com uma organização pública ou privada, que manifesta por escrito seu compromisso de administrar os fundos outorgados, assim como ser a contraparte executora do projeto. $\mathrm{O}$ financiamento dessa linha de ajuda é estabelecido nas reuniões anuais do Comité Intergovernamental e correspondem a uma porcentagem do montante global que tem sido contribuído anualmente pelos países participantes. De acordo com Pacheco (2017) o montante a que um Projeto Especial pode aspirar é determinado pelo Comité Intergovernamental. 
RELACult - Revista Latino-Americana de Estudos em Cultura e Sociedade

Revista Latinoamericana de Estudios en Cultura y Sociedad | Latin American Journal of Studies in Culture and Society V. 05, ed. especial, mai., 2019, artigo n ${ }^{\circ} 1560$ | claec.org/relacult | e-ISSN: 2525-7870

O impacto do Iberescena em cifras tem crescido de forma exitosa, o projeto movimentou, de acordo com o último relatório, cerca $€ 10.377 .350$ (PACHECO, 2017). Até o ano de 2017 foram recebidos 4.523 projetos, sendo que foram aprovados cerca de 1.024 projetos em dez anos de existência, leia-se 10 chamadas públicas, como podemos observar nos gráficos que seguem.

Gráfico 1. Projetos recebidos

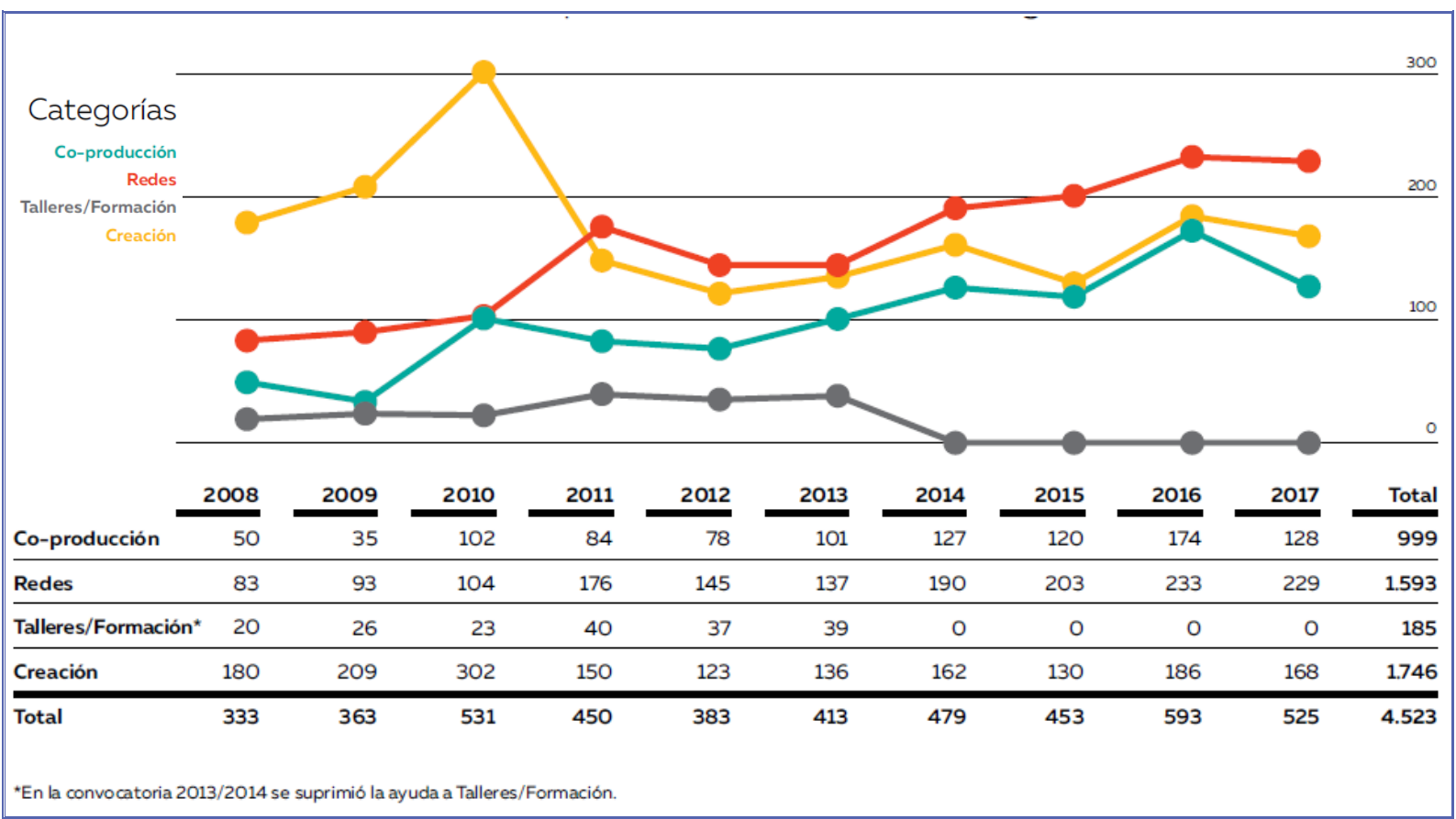

Fonte: (PACHECO, 2017)

Gráfico 2. Projetos apoiados

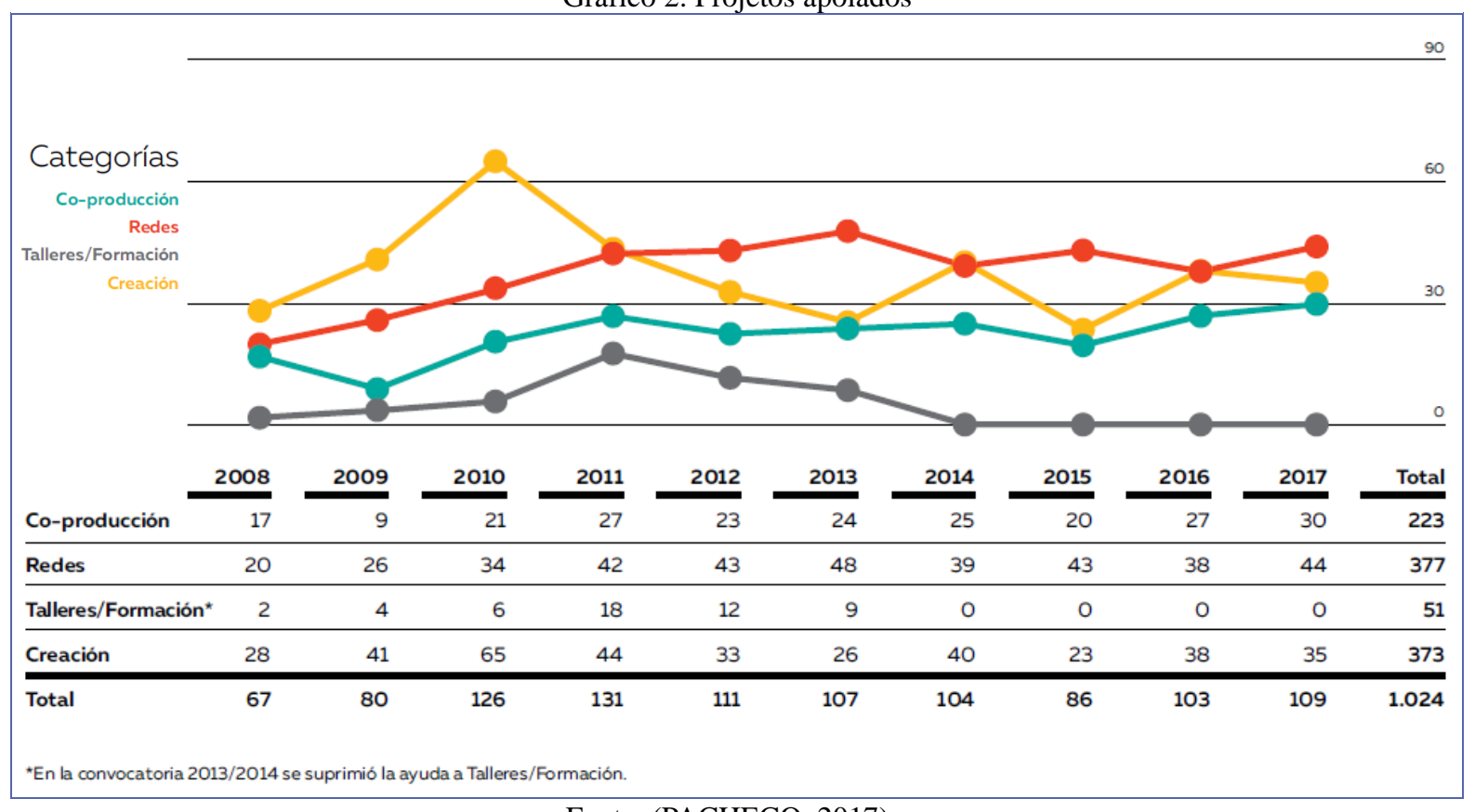

Fonte: (PACHECO, 2017) 
Neste contexto, de exposição de dados e "números" entendemos que a produção e discussão, não só desses indicadores que retratam o programa, mas de todos aqueles concernentes ao campo da cultura se fazem imperativos. É a partir deles que podemos empoderar a cultura enquanto política pública e setor que deve receber investimento. Além disso, os indicativos concretizam o discurso dos trabalhadores e fazedores da arte e da cultura de que o campo é um potencial vetor econômico. Voltando para o nosso objeto, ao observarmos os dados publicados pelo Portal Iberescena e pelos órgãos gestores em forma de informes e documentos podemos traçar um notável desenvolvimento no que se refere ao número de aportes econômicos injetados no fundo do Iberescena, fato que tem reflexo direto no número de projetos aprovados e no valor apoiado.

Gráfico 3. Indicadores de aportes fomentados

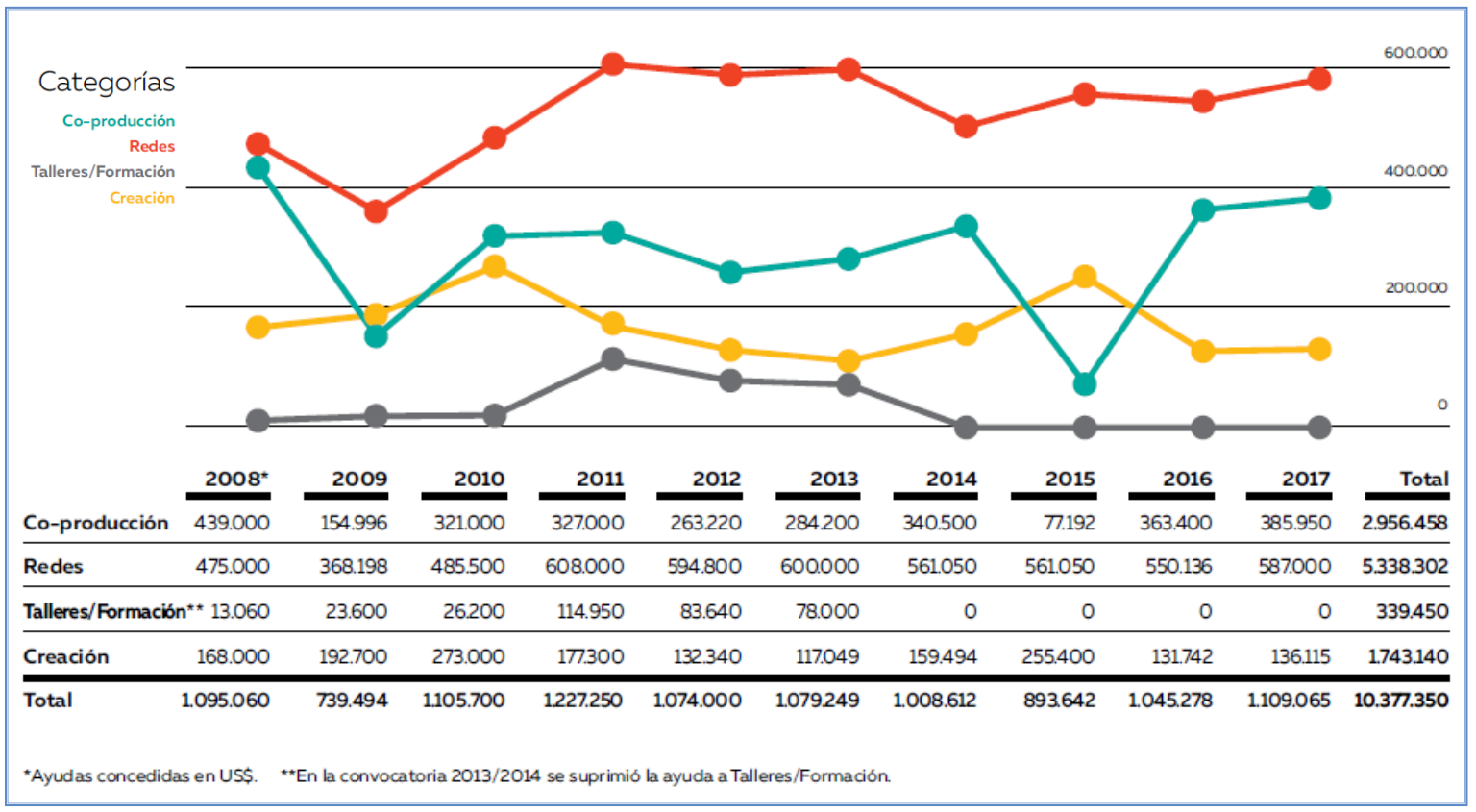

Fonte: (PACHECO, 2017)

\section{Algumas provocações}

Fica explícito, em nível teórico, que o programa se destaca pelo seu viés de democratização e desenvolvimento do setor das artes cênicas. No entanto, a lógica meritocrática dos editais acabam por hierarquizar e qualificar os projetos submetidos, esse é o outro lado da moeda por usarmos parâmetros neoliberais. Neste sentido, problematizamos a pertinência dos critérios de seleção, não só desta ferramenta de fomento, mas de tantas outras. 
No caso do Iberescena, a lógica, ou melhor, os critérios de seleção são baseados em quesitos e habilidades que os proponentes devem possuir ou se enquadrar, tais como: trajetória profissional dos coprodutores; trajetória da entidade organizadora do festival; a relevância da programação, etc. Entendemos que esses critérios fazem cair por terra todo o ideário de incentivo às pequenas produções, pequenos produtores e artistas iniciantes. A partir dessa perspectiva surgem diversas dúvidas sobre como produtores locais, ou aqueles iniciantes, sem uma longa carreira, ou até mesmo sem formação técnica, podem acessar e se beneficiar de um programa de fomento tão relevante como o Iberescena, e tantos outros. Infelizmente a lógica capitalista e meritocrática exclui os “já excluídos”.

É valido também, ter em conta uma certa dissemelhança quanto a forma de referir-se ao programa. Em termos regulatórios o Iberescena é caracterizado como um programa de apoio à construção de um espaço cênico ibero-americano, conforme o art. I do Regulamento de funcionamento do programa, bem como é promovido no site da SEGIB. Contudo, o Portal Iberescena, assim como seus editais, menciona o Iberescena como um fundo de ajudas para as artes cênicas ibero-americanas. Tal argumento aparentemente é percebido como algo de menor atenção, no entanto, esse fato implica numa divergência conceitual, dado que um programa compreende um corpus mais amplo de atividades, já a concepção delimitada de fundo deixa de fora possibilidades e ações de fomento que estão além da esfera econômica.

\section{Considerações finais}

Apesar de o programa ter algumas lacunas teóricas, e podemos dizer até mesmo operativas, tem um funcionamento fluido e orientado a resultados. Apesar de sua "juventude" é possível observar, de acordo com os indicadores, que ele ganhou certo protagonismo no cenário ibero-americano em decorrência de os países integrantes, mesmo alguns tendo uma política cultural voltada ao setor das artes cênicas, ainda se apresentam com demandas a serem supridas. Combinado a necessidade de criação de um espaço comum de trânsito cultural, promoção do conhecimento de artistas, produtores e gestores dentro do cenário ibero-americano. Em suma, sua característica multinível e cooperativa, reflete no aumento significativo de projetos submetidos ao longo de pouco mais de dez anos de existência. 


\section{Referências}

AGUIAR, Flavio Wolf de. A América Latina não existe. In: MARTINS, Maria Helena (Org.) Fronteiras Culturais - Brasil, Uruguai, Argentina. São Paulo: Ateliê Editorial, 2002. p. 65- 69.

BAYARDO, Rubens. ¿Cultura y desarrollo: Nuevos rumbos y más de lo mismo? In: NUSSBAUMER, Gisele Marchiori (Org.) Teorias e políticas da cultura. Salvador: EDUFBA, 2007. p. 67-94.

BENJAMIN, Walter. A obra de arte na era de sua reprodutibilidade técnica. In: Magia e Técnica, Arte e Política: Ensaios sobre Literatura e História da

Cultura. São Paulo: Brasiliense. 1994 p. 165-196.

BURITY. Joanildo. Cultura e desenvolvimento. In: NUSSBAUMER, Gisele Marchiori. Teorias e políticas da cultura: visões multidisciplinares. Bahia: EDUFBA, 2007. p.51-65.

CALABRE, L. Política cultural no Brasil: um histórico. In: (Org.). Políticas culturais: diálogo indispensável. Rio de Janeiro: Edições Casa de Rui Barbosa, 2005. p. 0920. (Coleção aconteceu na Casa de Rui Barbosa, v 1)

EAGLETON, Terry. A ideia de cultura. São Paulo: Editora UNESP, 2011.

ELIAS, Norbert. O processo civilizador, volume 1: uma história dos costumes. 2. ed. Trad. Ruy Jungmann. Rio de Janeiro: Zahar, 2011.

FERNANDES, Antonio. A mudança cultural na sociedade moderna. Revista de Comunicação e Linguagem, n. 6, 1988.

FÉRRIZ, Ramón González \& PONSÀ, Francesc Montserrat. Cooperación Cultural al desarrollo: herramientas para la reflexión. Barcelona: Líniazero Edicions/Fundació Casa Amèrica Catalunya, 2007.

FLORES, Alicia Pérez; MIGUEZ, Paulo César. A cooperação cultural na perspectiva da UNESCO: trajetória e expectativas. Políticas Culturais em Revista. v. 1, n. 8, p. 106-120, 2015. Disponível em: 〈www.politicasculturaisemrevista.ufba.br〉

HALL, Stuart. A centralidade da cultura: notas sobre as revoluções culturais do nosso tempo. Educação e Realidade. Porto Alegre, v. 22, n. 2, p. 15-46, jul./dez. 1997.

HERMET, Guy. Cultura e desenvolvimento. Trad. Vera Lúcia de Mello Joscelyne. Petrópolis: Vozes, 2002.

HOBSBAWM, Eric. Era dos extremos: o breve século XX (1914-1991). Trad. Marcos Santarrita. São Paulo: Companhia das Letras, 1995.

PACHECO, Carlos (org.) Iberescena 10 años: fondo de ayudas para las Artes Escénicas Iberoamericanas 2007-2017. Ciudad Autónoma de Buenos Aires: Inteatro, 2017.

RAMOS, Rúbia de Araújo. Sujeito na perspectiva de Alain Touraine. 151 p. Dissertação de Mestrado em Ciências Sociais. Universidade de Federal de São Paulo. Escola de Filosofia, Letras e Ciências Humanas, Guarulhos, 2013. 
SEGIB. Evaluación: Programa Ibero-americano de Cooperación. Santiago: Gestión y Contenido S.A., 2012.

VILLARINO, Julio; ZANABRIA, Juan Manuel. La cooperación cultural iberoamericana. Políticas Culturais em Revista, v. 2, n. 8, p. 243-259, 2015. Disponível em: <www.politicasculturaisemrevista.ufba.br>

YUDÍCE, George. El recurso de la cultura: usos de la cultura en la era global. Trad. Gabriela Ventureira. Barcelona: Editorial Gedisa, 2002.

\section{Documentos}

URUGUAI. 4 de novembro de 2006. Declaración de Montevideo. XV Cumbre de Jefes de Estado. Disponível em: 〈http://www.iberescena.org/institucional/declaracion-montevideo> Acesso em: 02 agosto 2017.

URUGUAI. 2006. Regulamento de Funcionamiento del Programa IBERESCENA. Disponível em: 〈http://www.iberescena.org/institucional/normativa-organica> Acesso em: 02 agosto 2017

PARIS. 4 de novembro de 1966. Declaración de los Principios de la Cooperación Cultural Internacional. UNESCO. Disponível em: <http://portal.unesco.org/es/ev.php$\underline{\text { URL_ID }=13147 \& U R L \_D O=D O \_T O P I C \& U R L \_S E C T I O N=201 . h t m l}>$. Acesso em: 20 maio 2018.

\section{Sítios}

Portal IBERESCENA. Disponível em: 〈http://www.iberescena.org>. Acesso em: 20 maio 2018.

Portal da Secretaría General Iberamericana. Disponível em: 〈https://www.segib.org/pt-br/> Acesso em: 20 maio 2018

Portal da Organização das Nações Unidas. A história da organização. Disponível em: <https://nacoesunidas.org/conheca/historia>. Acesso em: 20 maio 2018.

Portal da UNESCO. The Organization's history. Disponível em:〈http://www.unesco.org/new/en/unesco/about-us/who-we-are/history/>. Acesso em: 20 maio 2018. 